\title{
Using Arabic in an EFL Class: Bringing a New Approach to Using L1 in a Foreign Language Class
}

\author{
Suad Essam W. Mizher \\ Riyadh Al Hoda School, Al Jubail Industrial City, Saudi Arabia
}

\begin{abstract}
Can Arabic be an unconventional method for teaching English? This research will describe how the teacher used some Arabic language methods as a teaching strategy to improve her EFL students' reading, writing, and understanding of English grammar. The research took place over a period of two years in Lebanon and four years in Saudi Arabia. Data consists of comparative tables, videos of two samples of students using Arabic to learn English, and pictures of the teacher using Arabic for comparative in grammar. Results revealed an increase in the level of understanding and comprehension of students in both the elementary and intermediate levels.
\end{abstract}

Keywords: Arabic, diacritics, sentence structure, grammar, vowels

\section{Introduction}

When I applied for my first job in Lebanon as an English teacher in an English based school, the custom was that I attend several classes at the beginning to observe how the teaching process goes and to choose the correct level for me to teach. The honorable headmistress was very strict in the subject that no Arabic was allowed in an English session. On the first day, I attended a class in kindergarten level 1. The teacher was introducing the letter A and singing ( $\mathrm{A}$ is for apple. A is for ant). I clearly remember the look of bewilderment on the faces of the young learners. They did not know what an apple or an ant is. Even after the teacher presented pictures, which changed the session from a Letter Recognition class to Vocabulary lesson, it took them a long time to recognize what is an apple or an ant not to mention the time to explain the meaning of a letter.

It was decided that I teach elementary levels Grades 4 to 6 . Everything went smoothly with the students who originally studied at the school from the KG. But these were just a handful. The problem aroused when new or transferred students came from Arabic based schools. They lacked the basic foundations for reading and writing properly in English. For example, they would read (pat, put, pot, pet, pit) the same. They would write (write) as (rayt or rait). They did not grasp the concept of vowels because it was a strangely sounded word and we, teachers, were not allowed to use Arabic - their native language - to explain it to them.

One day in class, I was re-explaining to my students the difference between long and short vowels - a lesson that has taken me three periods more than planned — and my students were looking at me like I was talking Martian. This is when the idea suddenly came to me. These are Arab students. They have lived all their lives

Suad Essam W. Mizher, teacher of English as a Foreign Language, B.A. in English Literature, Riyadh Al Hoda School. 
listening, speaking, and using Arabic in their everyday routines. They will always think in Arabic even if they mastered the English language. So why not use Arabic as a tool to simplify some English concepts?

I started using the ideas referred to in the research and in just one session my students understood what I failed to do in five sessions using an-English-only education. I continued using them for a month without informing my headmistress. My students' grades jumped from average to good reaching very good by the end of the year. Their drastic improvement caused a joyous bewilderment amongst the faculty. I knew I was going to be questioned about the undisclosed method leading to my ideas being shut down. That is why I had to be prepared with references and statistical studies to back me up.

\section{Research Summary}

Probably, the minute one hears the words "Arabic in class" one would think of Translation. In the past, EFL teachers would use Arabic as a mere translation tool to explain challenging words or concepts; maybe even some educators would spend most of the class time talking in Arabic under the conception that it is easier for both them and their students. That is why many researchers published against the usage of Arabic inside ESL or EFL classrooms arguing that a student will not learn a new language in a native language environment. ${ }^{1}$

However, we cannot keep denying the fact that we need Arabic to teach Arab students, especially young ones, the English language. After all, EFL teachers should understand that they are approaching Arabic minds that think with their mother language while trying to produce English. ${ }^{2}$

Although the research is about using Arabic L1 in an EFL class, it does not in any way endorse the using of word by word translation. On the contrary, this research will attempt to show how using some of the Arabic rules and grammar as a teaching strategy has drastically improved both reading and writing skills for Arab students. The researcher will also demonstrate links to recorded examples of her technique applied on her students of different levels.

\section{The Research's Method and Apaproach}

The research was formulated according to the SMART hypotheses.

S: Specific for the research is dealing only with using Arabic as an L1 in an L3 class.

M: Measurable using statistics of before and after impact studies.

A: Achievable in a way that this research is simple in execution by using already present methods.

$\mathrm{R}$ : Realistic in a way that it is directly related to the educational process and the improvement of the students' achievements.

T: Touchable for it approaches a critical problem and tries to find suitable solution.

\footnotetext{
${ }^{1}$ See Scott Thornbury at www.scotthornbury.wordpress.

2 See Juliane C. De La Campa, Hossein Nassaji's article: The Amount, Purpose, and Reasons for Using L1 in L2 Classrooms.
} 


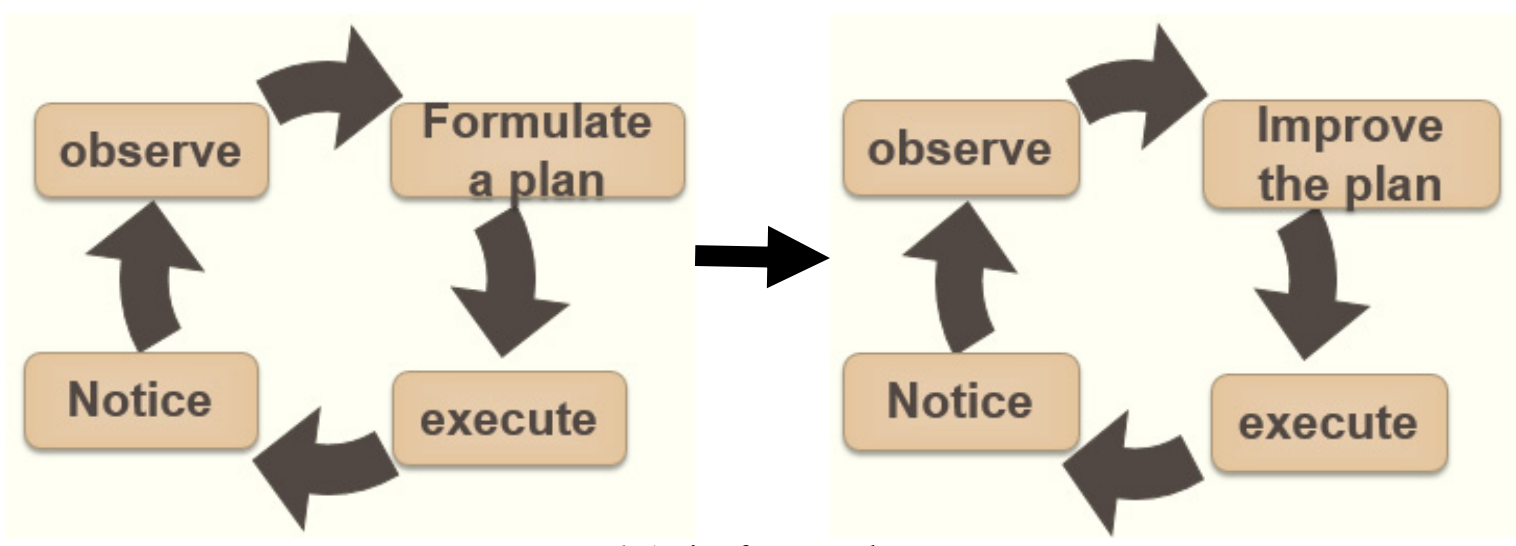

Figure 1. Action for research progress.

Vivian Cook (2001) writes about the mother tongue in EFL classes as "a door that has been firmly shut in language teaching for over a hundred years" (p. 403). That is why teachers often forget that when students come to the classroom they come "loaded" with their native language and a cultural heritage that nobody must deny or underestimate. However, the current norm states that the only way to learn a new language is to completely obliterate any use of the $\mathrm{L} 1$ in class.

The mother tongue represents a powerful resource that can be used in a number of ways to enhance learning but it must always be used in a principled way. ${ }^{3}$ Nevertheless, most—if not all—of these researches talk about the use of L1 as a translation tool. They argue that on one hand it would be easier for students to express their ideas and on the other it will help teachers show their humanistic side. ${ }^{4}$

The aim of this research is to find realistic solutions to problems facing teachers teaching English as a foreign language to Arab students. It also seeks to improve the quality of the level of Educational Attainment of EFL students. With this in mind, what the paper presents are completely different approaches to using L1 specifically Arabic to teach reading and writing English in an L3 class. The techniques used are the same methods used to help native Arab students learn reading and writing their language.

\section{The Area for This Research}

The research targeted over 200 elementary students and 48 intermediate over a period of two years in Lebanon and four years in Saudi Arabia

\section{The Predicaments}

(1) Weak students are not responding to the traditional way of teaching English sounds, vowels and letter blending;

(2) Almost $50 \%$ of students confuse the sounds of the consonant and vowel letters thus showing poor reading and writing skills;

(3) Almost 50\% of students do not show good spelling foundations and none of the lower level students know how to spell;

(4) Students of higher levels confuse the English grammar rules with that of the Arabic.

\footnotetext{
3 See Sheelagh Deller and Mario Rinvolucri's book Using the Mother Tongue.

${ }^{4}$ See John Harbord 1992.
} 
Steps for Applying the Program

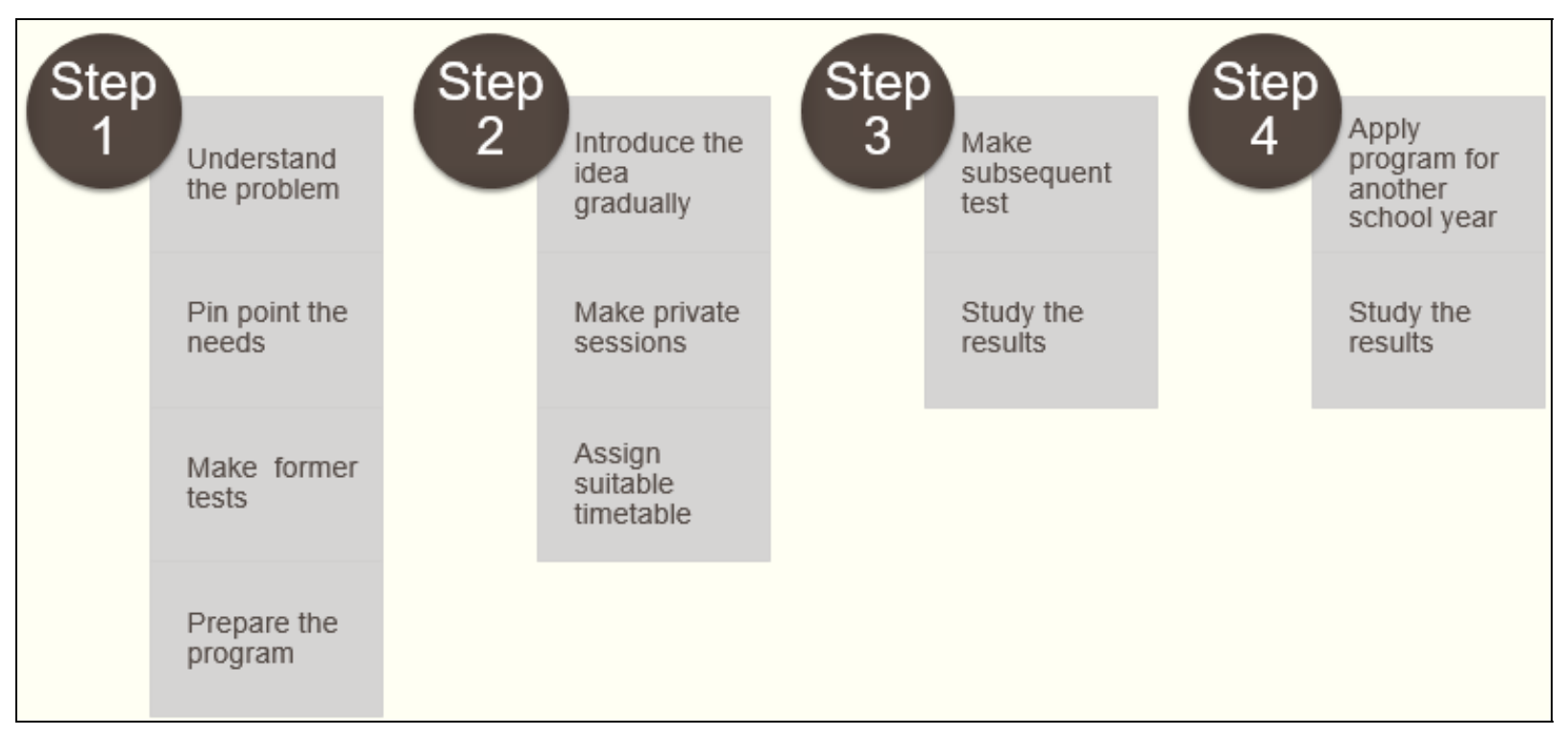

Figure 2. Steps for the program.

The Results and The Level of Improvement

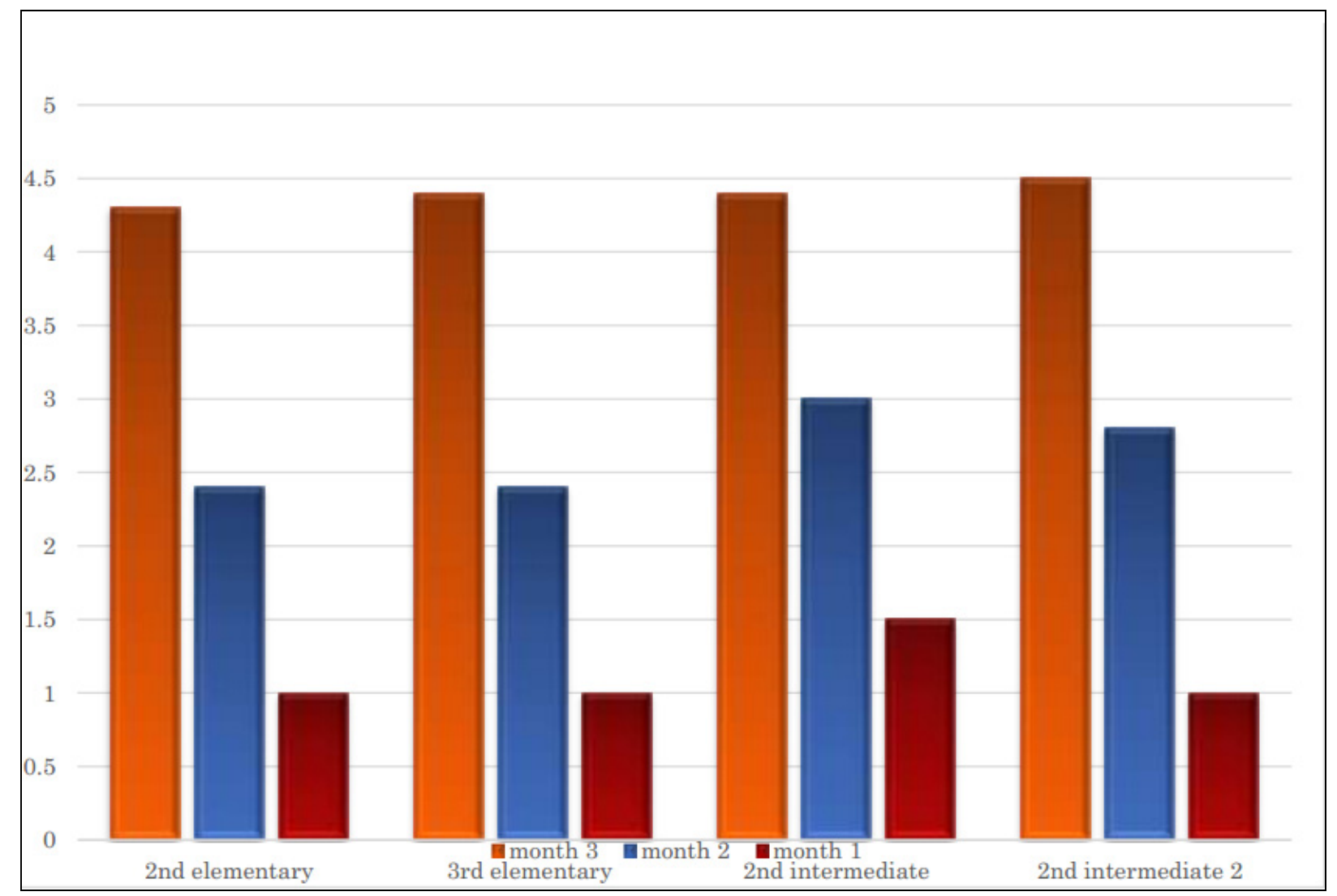

Figure 3. The results and the level of improvement. 
The above statistics took place over three months where the students were informally pre-tested at the first month and scored. The teaching methods mention later in the research are applied. Then the students were given a similar test in the second month and scored again. The methods are continued to be applied until a final test is given in the third month.

The results were unsurprisingly satisfying to prove the success of the method of using Arabic L1 in an English Foreign class.

The methods for this research takes the form of using two specific Arabic fields.

(1) Arabic diacritics;

(2) Arabic sentence structure.

\section{Using Arabic Diacritics}

In the Arabic language, there are 28 basic letters that are read in two conducts, short consonant sounds and consonants with long vowels sound. The short consonant sounds are represented by using Diacritics, tiny symbols drawn above or below the Arabic letter to help recognize the articulation of the letter and how it is pronounced. They also change the meaning of the world.

The figure below shows an example of the use of diacritics.

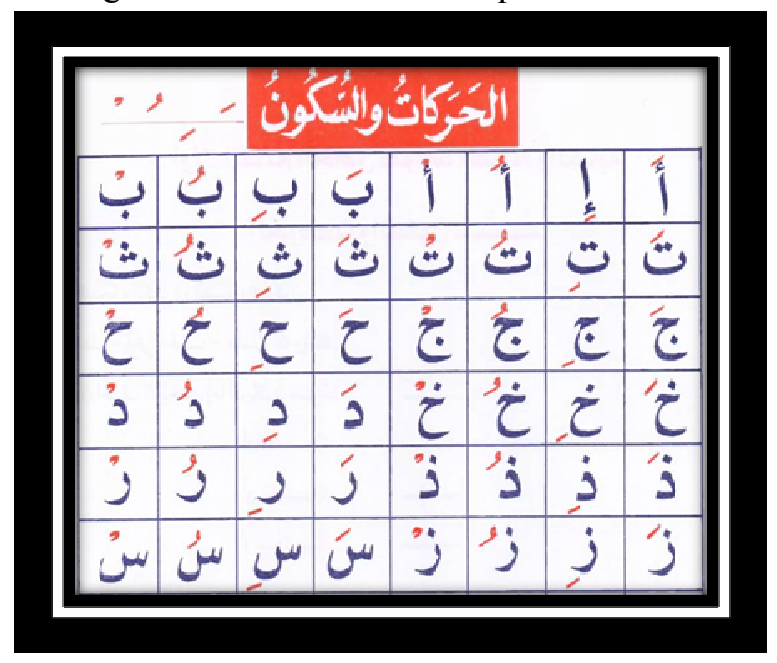

As an example, let us take a three letter word and see how the word's pronunciation and meaning changes as the diacritics change.

علم علم

Taught knowledge flag As noticed the letters are the same, but the changing of the diacritics changed the pitch and pronunciation and as a result the meaning of the word.

Figure 4. Arabic diacritics.

A special feature of the Arabic diacritics is that after the students master the reading skills, diacritics are no longer a necessity. And a higher level student can read without them.

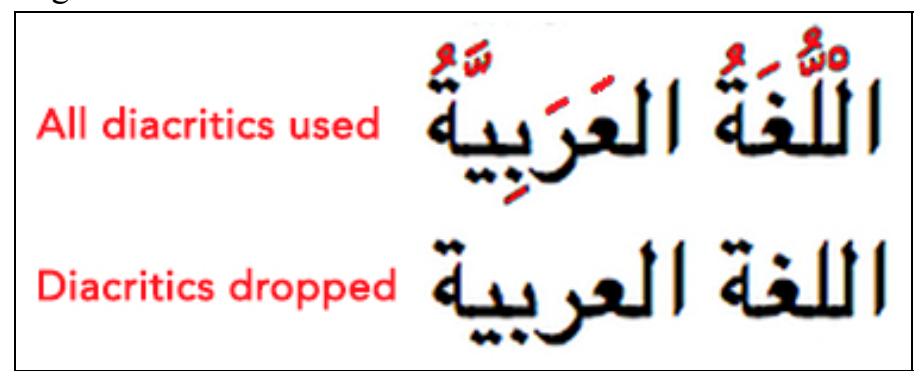

Figure 5. With and without diacritics. ${ }^{5}$

\footnotetext{
${ }^{5}$ Image credited to http://iconictranslation.com/2014/09/language-challenge-6-arabic/.
} 
Coming to the English language with its 26 letters, we notice a similarity with Arabic diacritics in the form of the vowels. The vowels in English serve also to determine the pitch and the pronunciation of the letter sounds which in turn changes the meaning of the word. Also, like in Arabic, the vowels have two conducts, short sounds and long sounds.

\begin{tabular}{|lc|cc|cc|cc|}
\hline \multicolumn{6}{|c|}{ Word Pairs - Short Vowel to Long Vowel } \\
\hline bit & bite & cub & cube & cut & cute & glob & globe \\
cap & cape & Jan & Jane & Sam & same & sag & sage \\
cod & code & man & mane & Sid & side & dot & dote \\
con & cone & mad & made & sit & site & pop & pope \\
Dan & Dane & mat & mate & tam & tame & bad & bade \\
dim & dime & not & note & tap & tape & glob & globe \\
fad & fade & pal & pale & Tim & time & grad & grade \\
\hline
\end{tabular}

Figure 6. Examples of short and long vowels usage.

However, the vowels are not represented, like in Arabic, in symbols. They stem from five letters (a, e, i, o, u). They are an essential part of the word and cannot at any time be eliminated, and here is where it gets confusing for Arab students. They often would write their names for example without a vowel or probably all the vowels like they do when writing them in Arabic without diacritics.

Nsrin (instead of Nisreen) for نسرين

Or they would switch the vowels because in their minds they are the same- especially the sounds of the vowels (o and $u$ ) and (e and i).

By simple comparison, one cannot help but notice the all too familiar resemblance between the English vowels and the Arabic diacritics, for they practically share the same pronunciations.

In Arabic, we have three main diacritics for short sounds:

(1) Al Fat-ha:

(2) Al Kas-ra:

(3) Al Dam-ma:

(4) Added to them is Al Sokoon: $\dot{\circ}$ as a stop sound

They become long sounds when added to them three letter $(9$, ,

If we look at an image featuring the pronunciation of the short vowel (a) and the diacritic Al Fatha, the resemblance will be undeniable. 

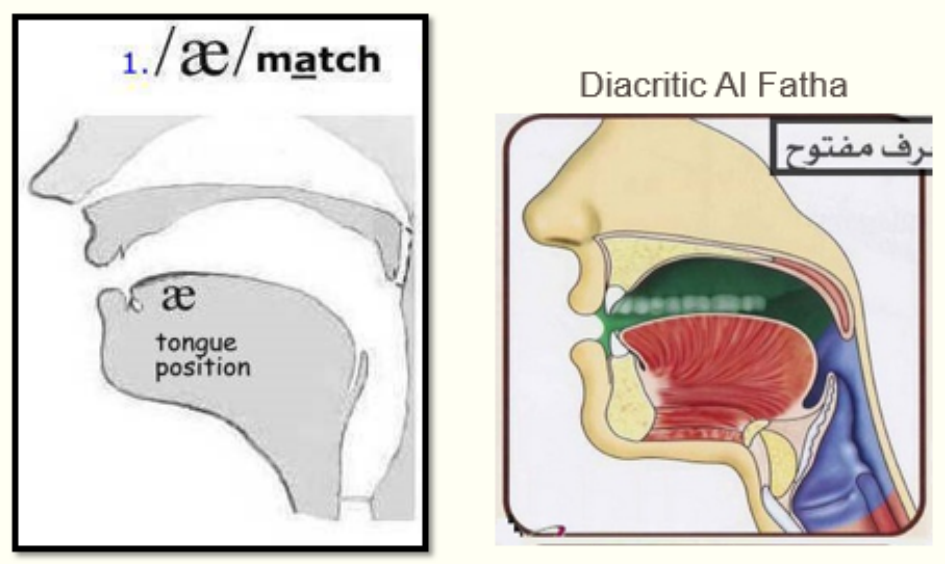

Figure 7. Short vowel a vs. Fatha diacritic.

The same for the short vowel (i) and the diacritic Al Kasra.
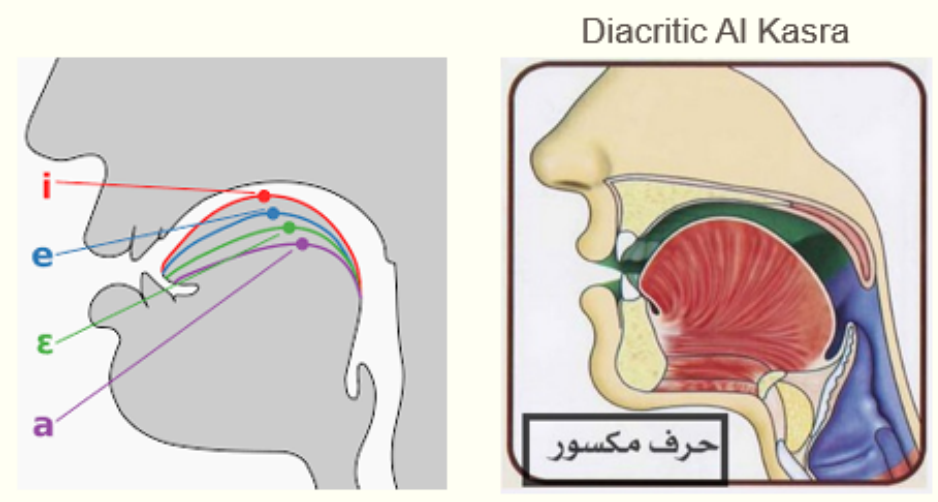

Figure 8. Short vowel i vs. Al Kasra diacritic.

So it is with the short vowel (o) and the diacritic Al Damma.
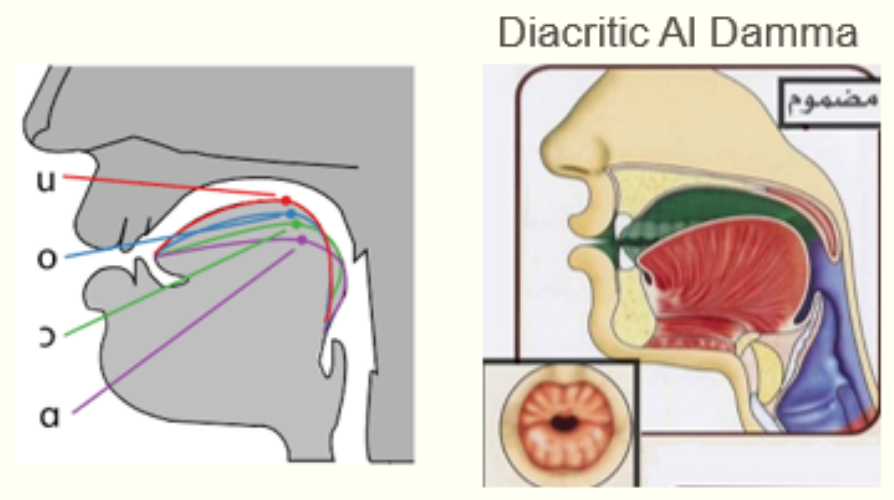

Figure 9. Short vowel o vs. Al Damma diacritic.

Accordingly, it would be very convenient to associate the English vowels with the Arabic diacritics for a better understanding of how the sounds are articulated.

"Students could write the Arabic diacritics on the English letters and vowels to read and write properly". 
The concept is simple. Three Arabic diacritics would represent three strong vowel sounds (a, i, o). While the $(\mathrm{e}, \mathrm{u})$ are the more week sounds.
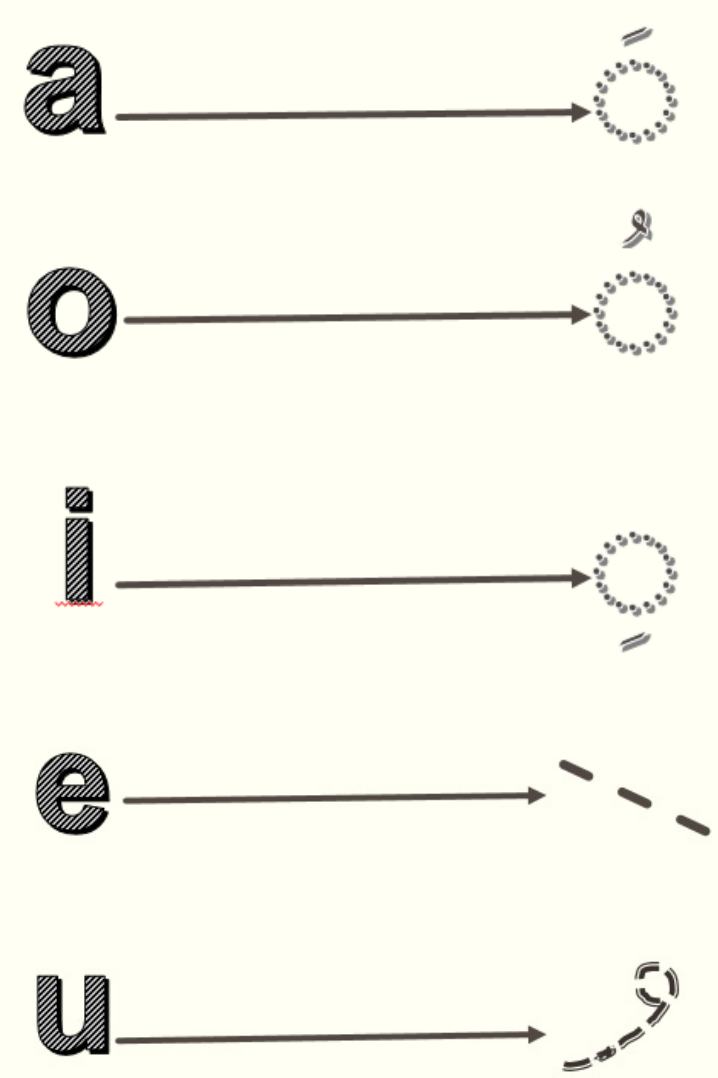

Figure 10. Associating vowels with diacritics.

When the vowels are represented by the three main diacritics, the rest of the consonant letters are represented by Al Sokoon.
$\begin{array}{ll}0 & 0 \\ B & C\end{array}$
$0 \quad 0$
O
$\begin{array}{lll}0 & 0 \\ H & J\end{array}$
O
$0 \quad 0$
D F
$\mathrm{G} \quad \mathrm{H}$
$\mathrm{K}$
L $\quad M$
$\begin{array}{ccccccccccc}\circ & \circ & \circ & 0 & 0 & 0 & 0 & 0 & 0 & 0 & 0 \\ \mathrm{~N} & \mathrm{P} & \mathrm{Q} & \mathrm{R} & \mathrm{S} & \mathrm{T} & \mathrm{V} & \mathrm{W} & \mathrm{X} & \mathrm{Y} & \mathrm{Z}\end{array}$

Figure 11. Letters with Sokoon.

In this manner, the teacher would guide the students to use the diacritics on a word with short vowels as a first step. 


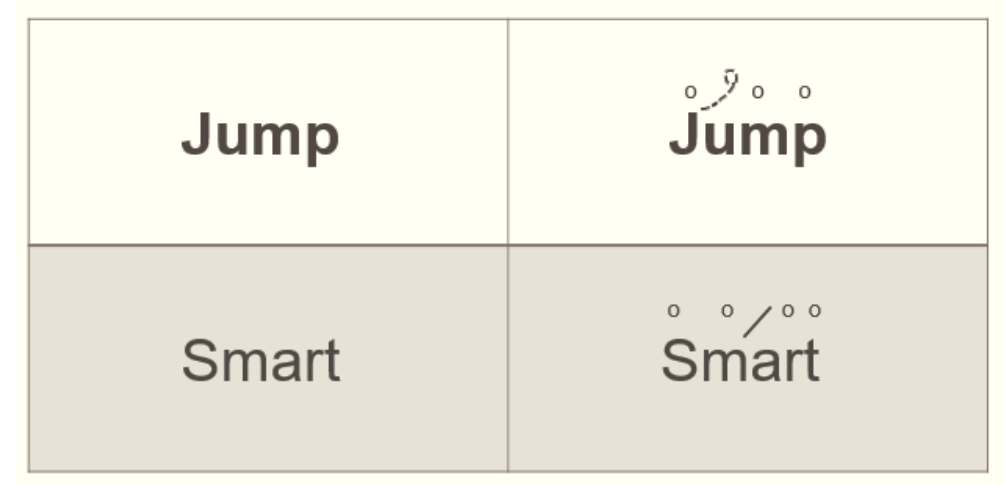

Figure 12. Using diacritics for English words.

Starting with young learners from the elementary level, giving them simple CVC, CVCC, or CCVC words, students start reading properly. Once they start mastering the reading and accepting the form of the use of the vowels their dictation will improve as thus.

The following link shows an excerpt of a student of the fourth elementary demonstrating the concept.

https://www.instagram.com/p/BCqF2_zhk4h/?taken-by=soso_english

When students master simple words with short vowels, the teacher could progress, in higher elementary levels, to explain long vowel sounds.

https://www.instagram.com/p/BCqHzrehk9O/?taken-by=soso_english

When this drastic point was presented in the TESOL Arabia Conference in Dubai 2016, one of the attendees aroused a critical question. Wouldn't the students rely on the diacritics all the time? And by doing this, would they always retain the mother tongue language when using English?

The simplicity of the answer lays in the nature of these diacritics in their mother tongue. Because as we stated before, gradually, as students progress in their educational levels of their L1, the need for diacritics to be present on the words diminishes until they vanish completely into the background. The same will happen when using them in English. They will be only used in the beginner level. And as students become more familiar in their reading abilities, the need for using the Arabic diacritics would reach the end.

\section{Using Arabic Sentence Structure}

EFL Arab students writing or producing English sentences face a problem of following the English criteria for a proper sentence structure. Even though on a general basis the English Sentence has a much simpler structure than its counterpart Arabic one, students were and still are noticed to face a confusion in its form. The reason is merely because Arab learners will always think Arabic in their minds when producing or writing another language. And as many researches on monolingual and bilingual use in classroom have argued, ${ }^{6}$ we can no longer ignore the impact on the mother tongue when teaching any foreign language. And this point has become inevitable especially when teaching in Arab countries.

To begin with, as most English teachers know, the English sentence almost has a fixed structure- (Subject + Predicate) or (Subject + Verb + Compliment). And whatever form the teacher chooses to convey, the English

${ }^{6}$ See C. J. Dodson's Language Teaching and the Bilingual Method. 
sentence must always have a verb. Sometimes the whole sentence is only one word and this word will be a verb: (sit down, stop...).

However, this is not the case for the Arabic sentence where the verb can precede the subject or it does not exist at all.

In Arabic, there are three structures of the sentence. A verb-sentence is a sentence that begins with a verb. A noun-sentence is a sentence that begins with a noun, and this sentence sometimes does not have a verb. A semi-sentence is a sentence incomplete in its structure but gives a meaningful concept.

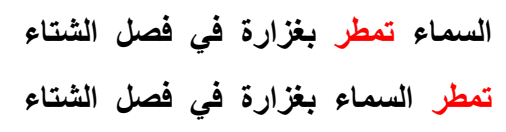

The words in red are the verb (rains). Both these sentences translate exactly the same in English.

The sky rains heavily in winter.

$$
\text { السماء جميلة في فصل الربيع }
$$

This sentence does not need a verb in the Arabic form. However, the translation is English requires one. Whereas, Arab beginners would write it without the verb to be.

Incorrect: The sky beautiful in spring.

Correct: The sky is beautiful in spring.

The problem increases when students compose questions in all their grammatical form. A question in English in most its cases requires the use or addition of a helping verb. This concept, however, is completely groundless in Arabic.

$$
\begin{gathered}
\text { لماذا السماء ملبدة بالغيومج a question with a lack of verb } \\
\text { Correct Translation: Why is the sky cloudy? } \\
\text { Wrongfully translated: Why sky cloudy? } \\
\text { a question with one simple past verb and no subject } \\
\text { Wrongfully translated: see movie yesterday? }
\end{gathered}
$$

The previous example poses yet another problematic issue. In Arabic, there is a rule where the subject is alluded to indirectly. This rule bares no similarity to the Passive Voice in English.

Many teachers - native or non-native - when teaching beginners' level in EFL Arab classes would report the same problem occurring whenever they ask students to compose sentences or questions.

Examples such as the following would be seen:

Go school me everyday.

Why you eat candy?

Teachers cannot comprehend why students fail to produce correct sentences and questions given that the rules in English are simpler and more stable than that of the Arabic. The answer is simply because Arab students have undergone intensive lessons teaching them the rules for their mother tongue compared to the two to three 
sessions per week for English. Add to that the fact that they use their Arabic language on a regular basis opposed to the rare occasions they use English outside their school.

If the Arabic L1 is forbidden to be used, the only way students would be able to maneuver such mistakes is through intensive courses in English of no less than three to four sessions per day. Nevertheless, this will be next to impossible in countries where English is not even the third or fourth language but taught as an extra-curricular foreign language.

What this research suggests is not a direct translation method but a mental one. The steps for execution are specific and simple

(1) The teacher must assert the order of which the English sentence or question are formulated;

(2) Students are allowed to compose the required sentence/question in Arabic mentally;

(3) Students substitute each field in the English structure with its counterpart in Arabic;

(4) The final correction is made.

A teacher asked the sixth elementary grade students to write sentences describing the everyday routine.

Students start by writing the form for the English sentence structure. They are allowed a specific time to compose the sentence in Arabic then assign each word to its proper place.

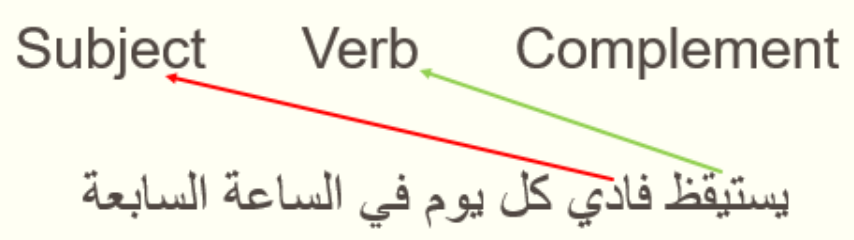

Figure 13. Producing a proper English sentence 1.

The students then would work in pairs or groups to write the sentence.

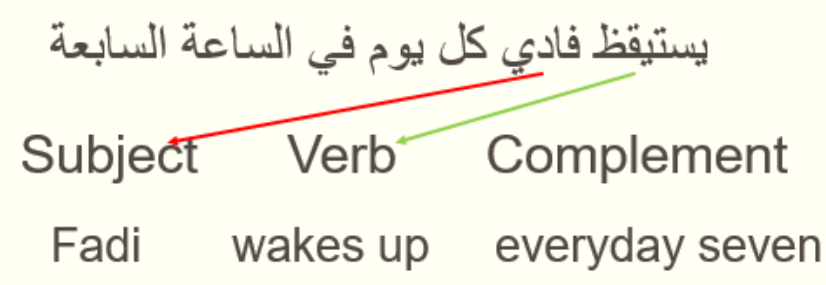

Figure 14. Producing a proper English sentence 2.

The final step would be to improve the final sentence

$$
\begin{array}{ll} 
& \text { يستيقظ فادي كل يوم في الساعة السابعة } \\
\text { Subject } \quad \text { Verb } & \text { Complement } \\
\text { Fadi } \quad \text { wakes up } & \text { everyday seven }
\end{array}
$$

Fadi wakes up everyday at seven o'clock. 
The same technique is applicable to forming a question.

As it was argued in the "Using Diacritics" section, this technique is only turned to in the beginners' level. And as students practice more, the need for using Arabic will decrease until it becomes a matter of fact.

\section{Conclusion}

As the testing of students throughout the time of the research and studying the results of these tests have shown a successful increase, using Arabic rules as a teaching strategy is possible and applicable. English teachers, especially non-native Arabic, can no longer ignore the impact L1 Arabic has on improving the quality of the English produced.

In his paper "We Only Learn Language Once. The Role of the Mother Tongue in FL Classrooms: Death of a Dogma”, Wolfgang Butzkamm says:

Using the mother tongue, we have learnt to think, learnt to communicate and acquired an intuitive understanding of grammar. The mother tongue is therefore the greatest asset people bring to the task of foreign language learning and provides a Language Acquisition Support System. ${ }^{7}$

Teaching any language as foreign, a teacher should never in anyway forget or try to erase the mother tongue from the educational procedure. After all, it is because of the L1 that students are able to read and write and have the confidence to learn a new language.

\section{References}

Butzkamm, W. (2003). The role of the mother tongue in FL classrooms: Death of a dogma. Language Learning Journal, 28, 29-39. Retrieved from http://www.fremdsprachendidaktik.rwthaachen.de/Ww/programmatisches/pachl.html

Cook, V. (2001). Second language learning and language teaching. Canada, Toronto: University of Toronto Press.

De La Campa, J., \& Nassaji, H., (2009). The amount, purpose, and reasons for using L1 in L2 classroom. Retrieved from www.onlinelibrary.wiley.com

Deller, S., \& Rinvolucri, M. (2002). Using the mother tongue. United Kingdom: Delta Publishing.

Dodson, C. J. (1967). Language teaching and the bilingual method. Retrieved from Wikipedia

Harbord, J. (1992). The use of the mother tongue in the classroom. ELT Journal. Retrieved from www.eltj.oxfordjournals.org

Thornbury, S. (2015). M is for mother tongue. Retrieved from www.scottthornbury.wordpress

\footnotetext{
${ }^{7}$ Language Learning Journal, Winter 2003, No. 28, pp. 29-39.

See http://www.fremdsprachendidaktik.rwth-aachen.de/Ww/programmatisches/pachl.html.
} 